\title{
Effect of Depth of Sowing on Seedling Emergence, Root Characters and Seed Quality Parameters in Wheat (Triticum aestivum L.)
}

\author{
Praveen K. Yadav, Monika A. Joshi*, Sudipta Basu and Atul Kumar \\ Division of Seed Science and Technology, ICAR-IARI, New Delhi, India \\ *Corresponding author
}

\section{Keywords}

Coleoptile length, Shoot length, Seed vigour indices, Root surface area, Root volume

Article Info

Accepted:

04 January 2019

Available Online:

10 February 2019

\section{A B S T R A C T}

The present study was conducted to study the effect of depth of sowing on seedling emergence, and correlation with coleoptile length in advance lines of wheat. The experimental material comprised of 60 wheat genotypes including certain advance lines and released varieties; and was carried out for two consecutive season viz. 2016-17 and 2017-18. These genotypes were categorised into three different coleoptile length groups i.e. short $(2.5-4.5 \mathrm{~cm})$, medium $(4.6-6.5 \mathrm{~cm})$ and long $(6.6-9 \mathrm{~cm})$ coleoptile length on the basis of observation in laboratory. All genotypes were sown at three different depths of $5 \mathrm{~cm}, 7.5 \mathrm{~cm}$ and $10 \mathrm{~cm}$ and replicated twice. The study revealed that the short and medium coleoptile length genotypes had less variation in emergence at all depths whereas the longer coleoptile length genotypes had significantly better field emergence. Coleoptile length was directly proportional to seedling shoot length i.e. short, medium and long coleoptile classes had an average coleoptile length of $7.12 \mathrm{~cm}, 8.87 \mathrm{~cm}$, and $12.60 \mathrm{~cm}$ respectively. Longer coleoptile length class genotypes also had higher SVI I and SVI II i.e. short, medium and long coleoptile classes had an average SV I value of 2051.8, 2198.11 and 2752.33 and SV II value of 42.3, 55.57 and 72.8 respectively. Larger coleoptile length was also in accordance with the higher root surface area, root volume and number of forks which provide genotypes early seedling vigour in stress conditions.

\section{Introduction}

The total land area of India is 329 million hectares of which 144 million hectares is arable land. Of this, 94 million hectares fall under dry lands constituting $65 \%$ of dryland and rainfed areas which produce $40 \%$ of the total food grains that feeds $40 \%$ of the total population. The remaining 50 million hectares constituting $35 \%$ of irrigated areas, account for $60 \%$ of the crop production. Dryland areas contribute significantly to wheat (Triticum aestivum $L$.) production, amounting to thirty three per cent of wheat production. Enhancing the production of dryland areas seems an attractive way to increase the productivity and production of wheat by introduction of alternate cropping system in rice-wheat areas. New production methodology like conservation agriculture can provide long term solution to all above raised issues. In the dryland area, upper soil moisture is depleted 
very rapidly after the sowing due to higher rate of evaporation. Hence depth of sowing in these areas becomes an important factor for field emergence in semi dwarf varieties of wheat. Thus the coleoptile length of the seedling becomes an important feature for the proper field emergence (Mohan et al., 2013). Similarly, moisture depletion takes place very rapidly with very early sowing of wheat due to presence of high temperature at that time. Thus higher depth of sowing facilitated by longer coleoptile length is of utmost importance for uniform establishment of crop for getting the higher productivity. Hence, higher crop yield is mainly dependent on the rapid and uniform field establishment of crop in the field, which is highly influenced by the sowing depth and the ability of the seedlings to emerge from the soil. Hence, the present study was conducted to study the effect of depth of sowing on seedling emergence, root characters and seed quality parameters in wheat.

\section{Materials and Methods}

The present study was undertaken during 2016-17 and 2017-18 at Division of Seed Science and Technology, IARI, New Delhi. The experimental material comprised of 60 wheat genotypes which were divided into three categories based on the coleoptile length of lines. These lines were denoted by code name (CLY Number); and are listed along with their respective pedigree (Table 1). The experiment was conducted in pots of size 15 $\mathrm{cm}$ diameter and $15 \mathrm{~cm}$ depth. Pot was filled with soil representing uniform moisture levels (11-12 \%) from various locations in the divisional field. Ten seeds for each genotypes were sown at varying depths of $5 \mathrm{~cm}, 7.5 \mathrm{~cm}$ and $10 \mathrm{~cm}$ and was replicated twice. The germination test was conducted as per ISTA 2015. Speed of germination was calculated by the formula as suggested by the Maguire (1962). For measuring the seedling length, ten normal seedlings were selected randomly for measuring root and shoot length and expressed in centimetres $(\mathrm{cm})$. After taking the final count of germination test, 10 normal seedlings from each replication were removed, washed, weighed and dried overnight at $80 \pm 1^{0} \mathrm{C}$. Seedling dry weight was expressed in $\mathrm{mg} /$ five seedlings. Vigour indices were calculated by the procedure as suggested by the Abdul-Baki and Anderson, 1973. For measuring coleoptile length, 25 seeds were kept on a moist germination paper with germ end down having $1 \mathrm{~cm}$ markings on either side of the central line, and kept in upright position at $20^{\circ} \mathrm{C}$ in dark and observation was taken on $10^{\text {th }}$ day. Roots obtained at $8^{\text {th }}$ day were separated from shoot by cutting and scanned in root scanner by the latest WinRHIZO software for root length, surface area, root volume and number of forks. In the present investigation the laboratory studies were analyzed by using completely randomized design (CRD). Star Nebula software obtained from website of IRRI was used for the data analysis and correlation between all the important parameters was calculated.

\section{Results and Discussion}

The coleoptile length of all the 60 genotypes was recorded and categorised as short (2.5-4.5 $\mathrm{cm})$, medium (4.6-6.5 cm) and long (6.6-9 $\mathrm{cm}$ ) (Table 1). Seed of each genotype was sown in pots under varying sowing depths of $5 \mathrm{~cm}, 7.5 \mathrm{~cm}$, and $10 \mathrm{~cm}$ and replicated twice. When short coleoptile length genotypes were sown at depths of $5 \mathrm{~cm}, 7.5 \mathrm{~cm}$ and $10 \mathrm{~cm}$ depths, average seedling emergence from $5 \mathrm{~cm}$ and $7.5 \mathrm{~cm}$ sowing depths was comparable to some extent i.e. $92.25 \%$ and $86.25 \%$ but the emergence from $10 \mathrm{~cm}$ sowing depth was drastically reduced to $58 \%$ (Fig. 1). For medium coleoptile length genotypes, average seedling emergence from $5 \mathrm{~cm}$ and $7.5 \mathrm{~cm}$ sowing depths was $97 \%$ and $86.75 \%$ and the 
emergence from $10 \mathrm{~cm}$ sowing depth was reduced to $70.75 \%$ (Fig. 2). For large coleoptile length genotypes, average seedling emergence from $5 \mathrm{~cm}$ and $7.5 \mathrm{~cm}$ sowing depths was $97.75 \%$ and $91 \%$. The emergence from deep sown condition averaged to $83 \%$ (Fig. 3) which was quite good as compared to short and medium coleoptile genotypes. Although there was a reduction in seedling emergence but it is sufficient to obtain a good plant stand in field condition. No definite relation could be established between speed of germination and genotypes of three different classes i.e. short $(2.5-4.5 \mathrm{~cm})$, medium (4.6-6.5 cm) and long $(6.6-9 \mathrm{~cm})$ coleoptile length genotypes. For each class, the speed of germination was 38.70, 38.20 and 39.60 respectively (Table 1 ). The speed of emergence is mainly dependent on the radical appearance which is a part of root initials, and no effect of GAR Rht genes on root length has been reported till date. Hence this explains the possible cause for nonexistence of any definite relation. The coleoptile length was directly proportional to seedling shoot length i.e. short $(2.5-4.5 \mathrm{~cm})$, medium $(4.6-6.5 \mathrm{~cm})$ and long $(6.6-9 \mathrm{~cm})$ coleoptile classes had on an average $7.12 \mathrm{~cm}$, $8.87 \mathrm{~cm}$, and $12.60 \mathrm{~cm}$ shoot lengths respectively (Table 1 ). This provides the long coleoptile genotypes an added advantage of better photosynthesis and dry matter accumulation over the short and medium coleoptile genotypes during early developmental stages and helps in better field establishment.

Similarly, the higher coleoptile length class genotypes had higher seedling vigour Index I and seedling vigour Index II. The short, medium and long coleoptile classes had on an average SV I value of 2051.8, 2198.11 and 2752.33 respectively and SV II values of 42.3, 55.57 and 72.8 respectively (Table 1). Hence, the longer coleoptile genotypes can provide better seedling emergence and ultimately better field establishment. Root biomass study is an efficient and rapid technique for assessment of the crop performance mainly for the initial growth stages which determines the early seedling vigour of crop. Surface area is main root biomass parameter which determines the early seedling vigour in wheat and results of the present study revealed that root surface area of different genotype classes i.e. short, medium and long coleoptile length had an average surface area of $6.23 \mathrm{~cm}^{2}, 7.52 \mathrm{~cm}^{2}$ and $8.55 \mathrm{~cm}^{2}$ respectively, where longer coleoptile length class genotypes had distinctly larger surface area; which leads to better seedling vigour and seedling establishment (Table 2). Similarly, longer coleoptile length genotypes had distinctly larger root volume than that of short and medium coleoptile length genotypes (Table 2). Root volume is also a major root biomass parameter responsible for early seedling vigour of wheat and from this study it is clearly evident that root volume of different genotype classes i.e. short $(2.5-4.5 \mathrm{~cm})$, medium (4.6-6.5 cm) and long $(6.6-9 \mathrm{~cm})$ coleoptile length had an average root volume of $0.089 \mathrm{~cm}^{3}, 0.110 \mathrm{~cm}^{3}$ and $0.131 \mathrm{~cm}^{3}$ respectively (Table 2). Number of forks is an important parameter of root biomass in crops like wheat having fibrous root structure, more is the number of forks more is the absorptive surface and more nutrient uptake results in good seedling establishment. From the study of number of forks, it is clearly evident that number of forks of different genotype classes i.e. short $(2.5-4.5 \mathrm{~cm})$, medium $(4.6-6.5 \mathrm{~cm})$ and long $(6.6-9 \mathrm{~cm})$ coleoptile lengths had an average 37.6, 42.8 and 56.5 number of forks respectively. Higher number of forks in genotypes of long coleoptile length class gives an advantage over other genotype classes and provides an early growth advantage also (Table 2). 
Table.1 Seed quality parameters for genotypes categorised under short, medium and long coleoptile length

\begin{tabular}{|c|c|c|c|c|c|c|}
\hline Genotypes & Pedigree & $\begin{array}{l}\text { Coleoptile } \\
\text { Length }(\mathrm{cm})\end{array}$ & $\begin{array}{l}\text { Speed of } \\
\text { Germinati } \\
\text { on }\end{array}$ & $\begin{array}{l}\text { Shoot } \\
\text { Length } \\
\text { (cm) }\end{array}$ & $\begin{array}{l}\text { Seed } \\
\text { Vigour } \\
\text { Index I }\end{array}$ & $\begin{array}{l}\text { Seed } \\
\text { Vigour } \\
\text { Index II }\end{array}$ \\
\hline \multicolumn{7}{|c|}{ Short coleoptile length genotypes } \\
\hline CLY1642 & 7 EBWYT 504 & 3.64 & 38.75 & 6.80 & 2210 & 41.25 \\
\hline CLY1647 & HD2874/HD2967//43rd IBWSN 1148 & 3.82 & 38.17 & 6.60 & 1964 & 36.26 \\
\hline CLY1648 & HD2874/HD2967//43rd IBWSN 1148 & 3.78 & 40.17 & 7.24 & 2084 & 49.86 \\
\hline CLY1649 & HD2874/HD2967//43rd IBWSN 1087 & 3.80 & 41.00 & 7.44 & 1999 & 38.41333 \\
\hline CLY1650 & HD2874/HD2967//43rd IBWSN 1087 & 3.50 & 37.33 & 6.58 & 1851 & 45.41333 \\
\hline CLY1652 & 10 SBWON-27//PBW 343/DW571 & 3.52 & 37.67 & 6.92 & 1996 & 47.09 \\
\hline CLY1653 & 31ESWYT-113//DW1272/HP1731 & 3.44 & 39.83 & 6.82 & 2020 & 42.88 \\
\hline CLY1656 & 31ESWYT-113//DW1272/HP1731 & 3.76 & 38.60 & 7.26 & 2024 & 50.21333 \\
\hline CLY1659 & $\begin{array}{l}\text { 31ESWYT- } \\
\text { 147/3/HW5028//HD2432/DW1309 }\end{array}$ & 4.56 & 38.25 & 7.74 & 2151 & 40.78667 \\
\hline CLY1662 & 18 HRWYT 214/18HRWYT-229 & 3.56 & 38.42 & 7.62 & 2022 & 37.85667 \\
\hline CLY1664 & 18 HRWYT 214/18HRWYT-229 & 3.90 & 36.42 & 6.82 & 2046 & 39.45 \\
\hline CLY1670 & HD 2824/VL804//PBW532/UP2425 & 3.58 & 40.75 & 7.00 & 1981 & 46.07 \\
\hline CLY1679 & EBWYT 60 & 3.54 & 36.42 & 7.00 & 2016 & 35.75 \\
\hline CLY1684 & Recombinant inbred line (RILs) & 3.98 & 37.50 & 7.30 & 1988 & 41.55 \\
\hline CLY1686 & $\begin{array}{l}\text { CL1449/PBW343//WL412/Vei/Koel/3/Pes/M } \\
\text { c-II }\end{array}$ & 3.48 & 39.08 & 7.80 & 1964 & 41.76 \\
\hline CLY1698 & 31 ESWYT 138/CSW23 & 3.80 & 39.90 & 7.00 & 2194 & 43.77333 \\
\hline CLY1708 & PBW343/CL1538//HD2932/HD2189 & 3.98 & 39.42 & 7.04 & 2119 & 29.80667 \\
\hline HD3086 & & 3.60 & 38.17 & 7.72 & 2238 & 43.08333 \\
\hline HD 3117 & & 4.26 & 38.58 & 8.24 & 2113 & 48.78 \\
\hline HD 2967 & & 3.86 & 39.67 & 7.38 & 2056 & 42.63 \\
\hline Mean & & 3.77 & 38.70 & 7.12 & 2051.8 & 42.3 \\
\hline \multicolumn{7}{|c|}{ Medium coleoptile length genotypes } \\
\hline CLY1601 & CL2596/K9451/CL882//HD2009 & 5.44 & 37.75 & 9.08 & 2404 & 53.36 \\
\hline CLY1610 & CL2596/K9451//CL882//HD2009 & 5.62 & 40.00 & 9.56 & 2347 & 56.12 \\
\hline CLY1622 & C-32 SAWSN 327 & 5.60 & 38.00 & 9.92 & 2417 & 50.92 \\
\hline CLY1632 & HD2953/HS365 & 5.30 & 40.08 & 9.16 & 2097 & 62.1 \\
\hline CLY1634 & SAWSN 3094 & 5.48 & 37.08 & 9.00 & 2105 & 55.18 \\
\hline CLY1635 & SAWSN 3097 & 5.66 & 35.17 & 7.98 & 2111 & 48.90667 \\
\hline CLY1638 & 18 HRWYT 214 & 5.44 & 38.00 & 9.44 & 2344 & 58.96 \\
\hline CLY1651 & HD2874/HD2967//43rd IBWSN 1087 & 4.86 & 39.92 & 7.78 & 1969 & 46.8 \\
\hline CLY1657 & $\begin{array}{l}\text { 31ESWYT- } \\
\text { 147/3/HW5028//HD2432/DW1309 }\end{array}$ & 4.96 & 36.00 & 9.30 & 2493 & 48.01333 \\
\hline CLY1676 & SAWSN 3194 & 5.42 & 38.58 & 9.26 & 2216 & 58.66667 \\
\hline CLY1677 & CSISA-HT-EM-37 & 5.32 & 38.17 & 9.06 & 2365 & 51.81333 \\
\hline CLY1678 & SRRSN 6083 & 5.26 & 34.25 & 8.68 & 2135 & 66.50333 \\
\hline CLY1680 & EBWYT 98 & 5.26 & 38.67 & 8.40 & 2049 & 61.64 \\
\hline CLY1681 & EBWYT 81 & 4.96 & 38.08 & 8.46 & 2365 & 60.45 \\
\hline CLY1692 & 31 ESWYT 135/CSW23 & 5.26 & 38.75 & 9.20 & 2083 & 64.72667 \\
\hline CLY1693 & 31 ESWYT $135 / \mathrm{CSW} 23$ & 5.04 & 39.17 & 9.36 & 2335 & 65.28 \\
\hline CLY1695 & $\begin{array}{l}31 \text { ESWYT } \\
\text { 135//HD2329/WR544/PBW343/NW3041 }\end{array}$ & 4.82 & 39.00 & 8.70 & 2342 & 59.63 \\
\hline CLY1701 & 31 ESWYT 138//PBW343/PH137/MC-II & 4.82 & 40.42 & 7.14 & 1852 & 45.56 \\
\hline
\end{tabular}




\begin{tabular}{|c|c|c|c|c|c|c|}
\hline CLY1707 & 31 ESWYT 138/CSW30 & 5.12 & 38.90 & 8.78 & 2101 & 46.62667 \\
\hline HD2329 & & 6.10 & 38.18 & 9.26 & 2187 & 50.16 \\
\hline Mean & & 5.29 & 38.20 & 8.87 & 2198.11 & 55.57 \\
\hline \multicolumn{7}{|c|}{ Long coleoptile length genotypes } \\
\hline CLY1606 & CL1633/ CNo. 601// CL1633/ CNo. 601 & 7.90 & 40.42 & 10.88 & 2771 & 69 \\
\hline CLY1611 & HD2967/NIVT-1A(3A) & 8.52 & 40.17 & 12.64 & 2566 & 72.63 \\
\hline CLY1612 & SAWYT-319(06-07) & 7.90 & 36.33 & 12.84 & 2492 & 65.86 \\
\hline CLY1613 & CP264//HD2839/ HD2329 & 8.46 & 39.00 & 13.48 & 2873 & 73.47 \\
\hline CLY1615 & HD2329/HDK-10//CBW38/WR541 & 8.34 & 39.58 & 11.62 & 2496 & 76.14 \\
\hline CLY1617 & IBWSN70//IBWSN 1053 & 8.42 & 40.83 & 12.64 & 2632 & 79.2 \\
\hline CLY1621 & C-32 SAWSN 179 & 7.40 & 40.17 & 11.88 & 2437 & 68.38 \\
\hline CLY1630 & HD 2878/HD29 & 8.36 & 38.42 & 13.24 & 3059 & 72.94333 \\
\hline CLY1636 & EBWYT 21 & 7.96 & 38.83 & 12.84 & 2934 & 70.17333 \\
\hline CLY1641 & 28 SAWSN 3157 & 8.22 & 40.25 & 12.30 & 2900 & 77.08 \\
\hline CLY1644 & VL 616 (2) Inqulab/Kundan & 8.90 & 37.83 & 12.72 & 2966 & 75.88 \\
\hline CLY1661 & 18 HRWYT 214/18HRWYT-229 & 8.30 & 40.34 & 12.82 & 2894 & 82.42667 \\
\hline CLY1668 & 18 HRWYT 222//VL849/UP2571 & 7.82 & 39.83 & 12.82 & 2562 & 68.14667 \\
\hline CLY1683 & SAWYT-331 & 7.68 & 41.58 & 13.02 & 2589 & 67.25 \\
\hline CLY1700 & 31 ESWYT 138//PBW343/PH137/MC-II & 7.36 & 41.58 & 11.60 & 2560 & 73.98 \\
\hline CLY1706 & 31 ESWYT 138/CSW30 & 8.52 & 38.25 & 13.64 & 2828 & 74.62 \\
\hline NP4 & & 7.66 & 42.75 & 12.32 & 2835 & 79.12667 \\
\hline NP818 & & 7.96 & 39.92 & 12.84 & 2866 & 72.15333 \\
\hline C 306 & & 7.96 & 39.33 & 13.12 & 2682 & 70.2 \\
\hline HDCSW18 & & 7.42 & 36.58 & 12.84 & 2937 & 67.34 \\
\hline Mean & & 8.05 & 39.60 & 12.60 & 2752.33 & 72.8 \\
\hline C.D. at $5 \%$ & & 0.136847 & 0.798616 & 0.337539 & 45.8302 & 0.798616 \\
\hline
\end{tabular}

Table.2 Root characters for genotypes categorised under short, medium and long coleoptile length

\begin{tabular}{|l|c|c|c|}
\hline Genotypes & $\begin{array}{l}\text { Surface area } \\
\text { (cm }^{2}\end{array}$ & $\begin{array}{l}\text { Root } \\
\text { volume } \\
\left(\mathbf{c m}^{3}\right)\end{array}$ & $\begin{array}{l}\text { Number of } \\
\text { forks }\end{array}$ \\
\hline Short coleoptile length genotypes \\
\hline CLY1642 & 6.604 & 0.0822 & 34 \\
\hline CLY1647 & 6.814 & 0.0837 & 45 \\
\hline CLY1648 & 6.686 & 0.0992 & 42 \\
\hline CLY1649 & 6.218 & 0.0776 & 31 \\
\hline CLY1650 & 5.076 & 0.0896 & 37 \\
\hline CLY1652 & 5.224 & 0.0783 & 44 \\
\hline CLY1653 & 5.726 & 0.1032 & 40 \\
\hline CLY1656 & 3.78 & 0.1024 & 32 \\
\hline CLY1659 & 5.682 & 0.0678 & 37 \\
\hline CLY1662 & 7.14 & 0.1148 & 35 \\
\hline CLY1664 & 5.65 & 0.0876 & 41 \\
\hline CLY1670 & 6.326 & 0.1058 & 40 \\
\hline CLY1679 & 6.34 & 0.0982 & 33 \\
\hline CLY1684 & 7.476 & 0.0762 & 36 \\
\hline CLY1686 & 6.886 & 0.108 & 43 \\
\hline CLY1698 & 7.126 & 0.0854 & 32 \\
\hline CLY1708 & 7.026 & 0.1056 & 36 \\
\hline
\end{tabular}




\begin{tabular}{|c|c|c|c|}
\hline HD3086 & 5.876 & 0.0916 & 42 \\
\hline HD 3117 & 5.868 & 0.0712 & 38 \\
\hline HD 2967 & 6.544 & 0.0534 & 34 \\
\hline Mean & 6.23 & 0.089 & 37.6 \\
\hline \multicolumn{4}{|c|}{ Medium coleoptile length genotypes } \\
\hline CLY1601 & 7.246 & 0.112 & 43 \\
\hline CLY1610 & 7.654 & 0.114 & 47 \\
\hline CLY1622 & 7.95 & 0.108 & 38 \\
\hline CLY1632 & 6.38 & 0.0991 & 41 \\
\hline CLY1634 & 7.273 & 0.1028 & 45 \\
\hline CLY1635 & 7.158 & 0.1074 & 38 \\
\hline CLY1638 & 8.152 & 0.1268 & 48 \\
\hline CLY1651 & 7.478 & 0.1162 & 50 \\
\hline CLY1657 & 7.132 & 0.0874 & 42 \\
\hline CLY1676 & 7.761 & 0.128 & 46 \\
\hline CLY1677 & 7.864 & 0.119 & 46 \\
\hline CLY1678 & 7.886 & 0.1056 & 36 \\
\hline CLY1680 & 7.486 & 0.1224 & 39 \\
\hline CLY1681 & 7.784 & 0.0982 & 43 \\
\hline CLY1692 & 7.662 & 0.119 & 46 \\
\hline CLY1693 & 7.26 & 0.124 & 42 \\
\hline CLY1695 & 7.378 & 0.1064 & 38 \\
\hline CLY1701 & 8.206 & 0.1023 & 42 \\
\hline CLY1707 & 7.508 & 0.1096 & 42 \\
\hline HD2329 & 7.356 & 0.0983 & 44 \\
\hline Mean & 7.52 & 0.110 & 42.8 \\
\hline \multicolumn{4}{|c|}{ Long coleoptile length genotypes } \\
\hline CLY1606 & 8.068 & 0.1196 & 47 \\
\hline CLY1611 & 8.824 & 0.1308 & 53 \\
\hline CLY1612 & 8.816 & 0.137 & 46 \\
\hline CLY1613 & 8.903 & 0.1134 & 49 \\
\hline CLY1615 & 8.982 & 0.1334 & 57 \\
\hline CLY1617 & 8.21 & 0.1098 & 63 \\
\hline CLY1621 & 8.81 & 0.1384 & 54 \\
\hline CLY1630 & 8.212 & 0.1564 & 76 \\
\hline CLY1636 & 7.412 & 0.1384 & 53 \\
\hline CLY1641 & 9.424 & 0.1426 & 62 \\
\hline CLY1644 & 8.418 & 0.1254 & 59 \\
\hline CLY1661 & 8.134 & 0.1342 & 58 \\
\hline CLY1668 & 8.208 & 0.1234 & 60 \\
\hline CLY1683 & 9.208 & 0.1566 & 48 \\
\hline CLY1700 & 8.778 & 0.1346 & 61 \\
\hline CLY1706 & 8.444 & 0.1376 & 55 \\
\hline NP4 & 8.312 & 0.1128 & 56 \\
\hline NP818 & 8.618 & 0.1172 & 47 \\
\hline C 306 & 8.414 & 0.1314 & 59 \\
\hline HDCSW18 & 8.89 & 0.133 & 67 \\
\hline Mean & 8.55 & 0.131 & 56.5 \\
\hline C.D. at $5 \%$ & 0.321917 & 0.445196 & 0.679235 \\
\hline
\end{tabular}


Fig.1 Seedling emergence of short $(2.5-4.5 \mathrm{~cm})$ coleoptile length genotypes from different sowing depths

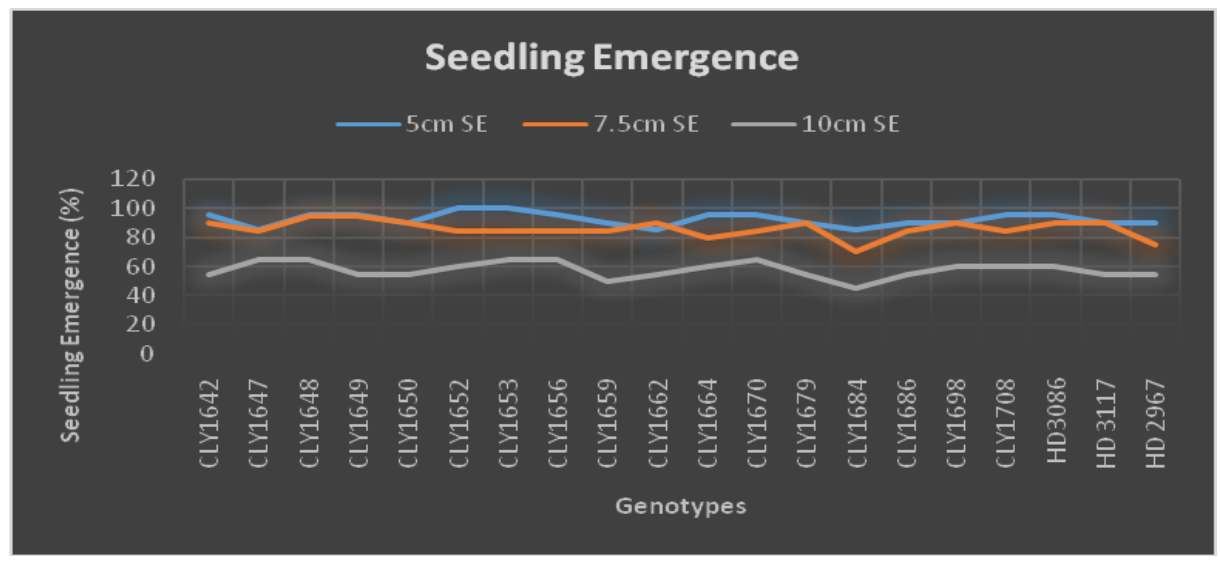

Fig.2 Seedling emergence of medium $(4.6-6.5 \mathrm{~cm})$ coleoptile length genotypes from different sowing depths

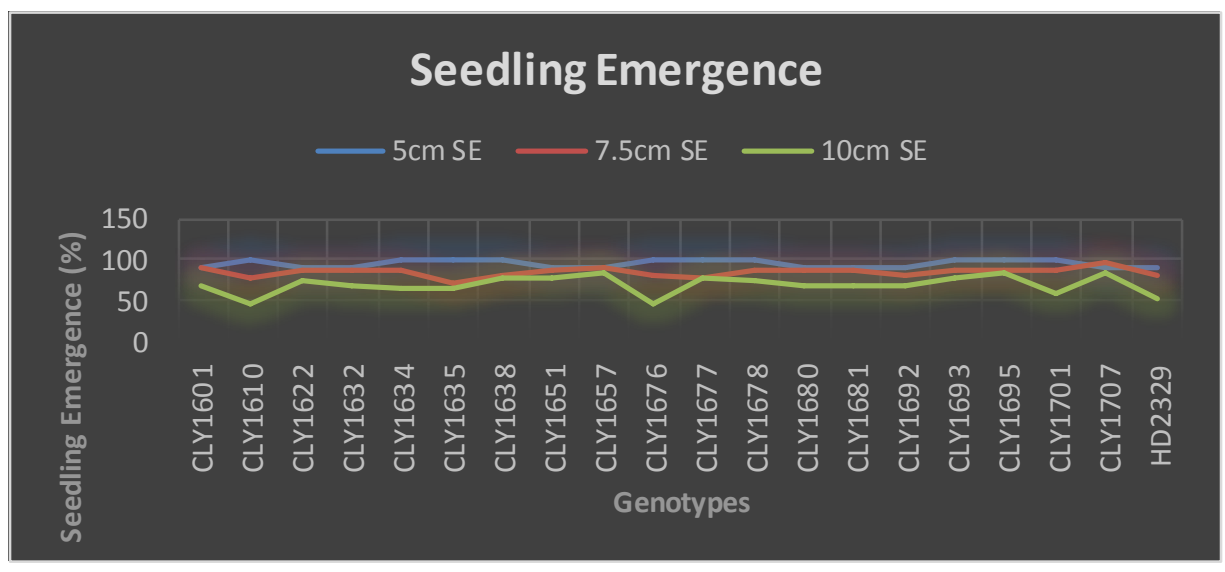

Fig.3 Seedling emergence of long $(6.6-9 \mathrm{~cm})$ coleoptile length genotypes from different sowing depths

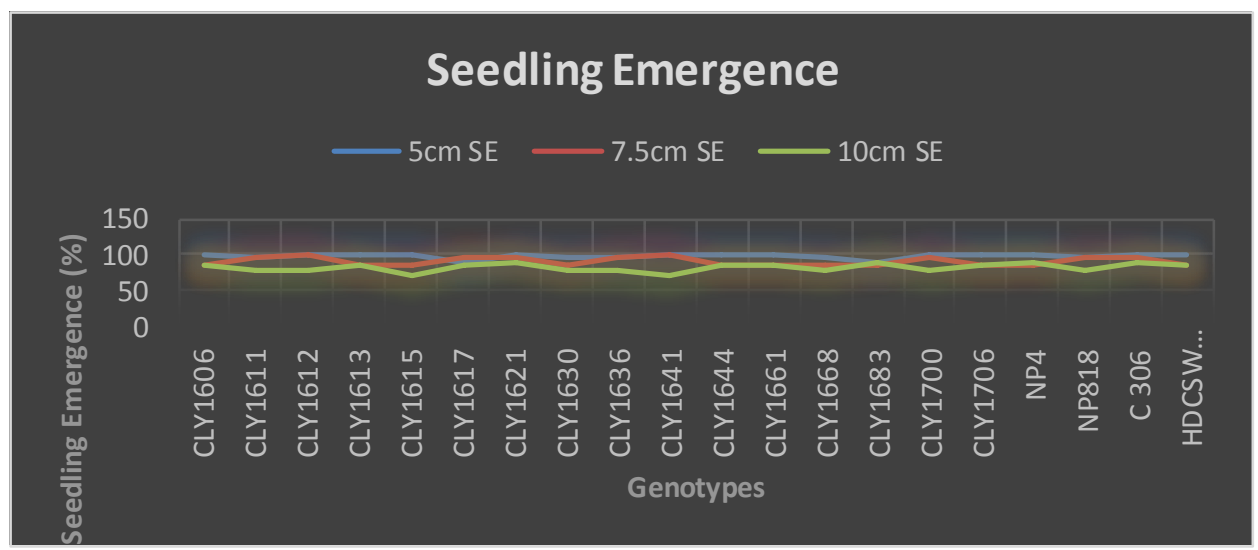


Hence from above observations it is concluded that longer coleoptile length class had longer emergence and early seedling vigour as compared to short and medium coleoptile length classes.

The study revealed that the short and medium coleoptile length genotypes had less variation in emergence from $5 \mathrm{~cm}$ and $7.5 \mathrm{~cm}$ depths of sowing.

On the other hand emergence from $10 \mathrm{~cm}$ depth was drastically reduced by $34.25 \%$ and $28.25 \%$ in short coleoptile length genotypes and by $26.25 \%$ and $16 \%$ in medium coleoptile genotypes respectively from the emergence from $5 \mathrm{~cm}$ and $7.5 \mathrm{~cm}$ sowing depths. Similar results were found by Amram et al., (2015); Chen et al., (2013); Rebetzke et al., (2005). The study of seedling vigour index and its relationship with the coleoptile length provides conclusive evidence that genotypes with longer coleoptile had greater early seedling vigour in field than short and medium coleoptile length class of genotypes. Similar results were also repeated by Rosyara et al., (2009).

The longer coleoptile length class of genotypes consistently had greater root surface area, root dry weight, root volume and number of forks per seedling which enhanced their capacity to absorb water from deeper soil profile and increasing number of forks also enhance the capacity to increase specific surface area and hence had capacity to perform well in dryland areas and similar findings were repeated by Rosyara et al., (2009).

\section{References}

Abdul-Baki, A. A., and Anderson, J. D. 1973. Vigor determination in soybean seed by multiple criteria 1 . Crop science, 13(6), 630-633.

Amram, A., Fadida-Myers, A., Golan, G., Nashef, K., Ben-David, R., and Peleg, Z. 2015. Effect of GA-sensitivity on wheat early vigor and yield components under deep sowing. Frontiers in plant science, 6, 487.

Chen, L., Phillips, A. L., Condon, A. G., Parry, M. A., and Hu, Y. G. 2013. GA-responsive dwarfing gene Rht12 affects the developmental and agronomic traits in common bread wheat. PLoS One, 8(4), e62285.

Maguire, J. D. 1962. Speed of GerminationAid in selection and evaluation for seedling emergence and vigor I. Crop science, 2(2), 176-177.

Mohan, A., Schillinger, W. F., and Gill, K. S. 2013. Wheat seedling emergence from deep planting depths and its relationship with coleoptile length. PLoS One, 8(9), e73314.

Rebetzke, G. J., Bruce, S. E., and Kirkegaard, J. A. 2005. Longer coleoptiles improve emergence through crop residues to increase seedling number and biomass in wheat (Triticum aestivum L.). Plant and soil, 272(1-2), 87-100.

Rosyara, U. R., Ghimire, A. A., Subedi, S., \& Sharma, R. C. 2009. Variation in south Asian wheat germplasm for seedling drought tolerance traits. Plant Genetic Resources, 7(1), 88-93.

\section{How to cite this article:}

Praveen K. Yadav, Monika A. Joshi, Sudipta Basu and Atul Kumar. 2019. Effect of Depth of Sowing on Seedling Emergence, Root Characters and Seed Quality Parameters in Wheat (Triticum aestivum L.). Int.J.Curr.Microbiol.App.Sci. 8(02): 143-150.

doi: https://doi.org/10.20546/ijcmas.2019.802.017 